\title{
The Search for Smartness in Working, Living and Organising: Beyond the 'Technomagic'
}

\author{
Editorial for Special Issue of Information Systems Frontiers
}

\author{
Amany Elbanna ${ }^{1} \cdot$ Yogesh Dwivedi $^{2} \cdot$ Deborah Bunker $^{3} \cdot$ David Wastell $^{4}$ \\ Published online: 28 April 2020 \\ (C) Springer Science+Business Media, LLC, part of Springer Nature 2020
}

\section{Introduction}

The significant advancement in the fields of electronics and computer science has produced innovation in devices and systems. For example, the miniaturisation of electronic components and devices combined with the evolution of wireless distributed networks have significantly enabled mobility and the connectivity of devices. Also, advances in sensor technologies have allowed ubiquitous objects to measure performance and transmit information regarding their functional state and their operating environment in a more reliable and low-cost way. These technologies enabled the development of mobile devices and wearable electronics. In addition, Web 2.0, fast-speed computing and efficient data storage have facilitated the emergence of new generation of data analytics and machine learning. Taken together, these plethora of new advanced technologies offer numerous possibilities and pitfalls for users. It is argued that they will change our world and whatever we do at work, home, leisure and even during times of crisis (Elbanna et al. 2019; Hughes et al. 2019;

Amany Elbanna

Amany.elbanna@rhul.ac.uk

Yogesh Dwivedi

y.k.dwivedi@swansea.ac.uk

Deborah Bunker

deborah.bunker@sydney.edu.au

David Wastell

David.Wastell@nottingham.ac.uk

1 School of Business and Management, Royal Holloway University of London, Egham, UK

2 Emerging Market Research Center (EMaRC), School of Management, Swansea University, Swansea, UK

3 The University of Sydney, H70 - Abercrombie Building, Sydney, NSW 2006, Australia

4 Business School, Nottingham University, Nottingham, UK
Ismagilova et al. 2019a, b; Kim et al. 2016; Papagiannidis and Marikyan 2019; Rana et al. 2019; Bunker et al. 2019b; Stieglitz et al. 2018). One of the changes receiving currency is the capability of these technologies to be 'smart' and to make us 'smart'. While the the term 'smart' is used vaguely by management and in the corridors of policy makers, computer scientists typically associate it with the use of the internet, connected devices, embedded sensors and machine learning. In this special issue, we widen the definition of 'smart' from a narrow technically oriented view to a wider transformatory sociotechnical view that puts use, impact and outcomes at the heart of achieving smartness in working, living and organising. Smart here is defined as 'the intelligent and rational use of resources to work, organise and live efficiently and effectively, healthily and happily, to the benefits of individuals, society, humankind and planet earth'.

We initiated this special issue with a simple question; do we live smarter with new classes of technology and if so, how? We were seeking to find aspects of smartness in our contemporary working, living and organising and to progress our understanding of the vast array of new technologies that are being adopted everyday by individuals, organisations, industries and society. We aimed to advance our understanding of the human aspects of living and organising with these technologies. Therefore, we called for research from different contexts and facets of life to understand the adoption and organising principles of emerging smart devices and technologies in smart homes, smart cars, smart phones, smart government, smart cities and smart organisations. We asked critical questions such as who is becoming smart and what are they becoming smart about? Who are the "winners and losers" and what role does technology play? How are emerging technologies adopted and appropriated in everyday life and what impact are they having?

Our focus was to broaden the theoretical base of adoption and diffusion of technology in light of these new technologies and new challenges. We welcomed papers that focused on traditional diffusion of innovation theories (for example, 
Davis 1989, Dwivedi et al. 2019a; Rogers 2003; Venkatesh et al. 2003) and strongly encouraged critical thinking and development and utilisation of new, non-traditional and contextspecific conceptual lenses and viewpoints. We welcomed papers that focused on technology at home, in the workplace and as they apply to the delivery of public services. Our hope was to move forward in our understanding of different types of adoption and implementation contexts which include organisations, industries and society (Dwivedi et al. 2015; Bunker et al. 2019a; Bunker et al. 2015). We encouraged scholars to examine different types of organisations and sectors including those that have traditionally been less represented in IS research. For example, not-for-profit and voluntary sector organisations, building and construction, automotive, transportation and infrastructure as well as the energy sector are all industries where the adoption of technology has had critical impact yet receive little research attention.

\section{Smart: A Complex Achievement of Technology, Users and Organisations}

The current rhetoric of smartness in business and society presents strong belief in (and sometimes fear) of the enormous power of technology to 'revolutionise' our world and 'make' us achieve maximum use of resources in the most rational ways. It brings about strong technological determinism where the existence of technological systems and devices is believed to unquestionably provide straightforward positive and revolutionary effect. Wastell (2011) argues that this infatuation with the potency of technology reflects a form of magical thinking, which he designates 'Technomagic'.

In this regard, the existence of smart tools such as data analytics systems, machine learning technology, geographical tagging technology, advanced data science and algorithmic development, mobile devices, social media platforms and tracking systems is believed to directly lead to intelligent ways of living, working and organising (Akter et al. 2019; de Camargo Fiorini et al. 2018; Duan et al. 2019; Dwivedi et al. 2019b; Gupta et al. 2018; Sivarajah et al. 2017; Bunker and Sleigh 2018; Ehnis and Bunker 2019). The market rhetoric for many of these technologies revolves around improving predictability, achieving precision of business models and bringing about fast decisions and agile operations with high accuracy. This rhetoric assumes the existence of a 'neutral context' where technology moves freely as it were in a contextual vacuum to produce expected results. It ignores users, the context of use, the quality of data, the nature of the market and competition and also the context of design (Wastell and Cooper 1996; McMaster and Wastell 2005; Elbanna 2008; Elbanna and Linderoth 2015; Kaniadakis and Elbanna 2019). Indeed, under the assumption of an absence of environmental factors that could influence the design and operation of technology, technical systems could provide this expected smartness. In this assumed neutral context, machines 'rule' our world enforcing unprecedented objectivity, efficiency, effectiveness and organising capability while providing real-time processing and visualisation, individual profiling of users and individualised services, following users wherever and whenever they are, geographically tagging users and profiling them and providing cheap computing following a utility model. Table 1 presents some of the characteristics and functions of technological smartness that are believed to be transmitted from the technological domain to the social domain in a neutral environment.

However, technology studies and information systems research have, for many years, stressed the importance of the environment in moderating the impact of technology and producing unintended consequences. Indeed, research has highlighted that users, their context of use, corporate policies, organisational structure, power dynamics and design context play key roles on what and how technology impacts individuals, organisations and society (Wastell 1999; Bunker 2001; Wastell 2003; Wastell et al. 2004; Bunker et al. 2008). Studies have also highlighted that technology design is subject to many environmental factors including; designers' cultural background and experience, dominating logic; available organisational resources including the type and support of template development approaches and methods; presence or absence of participative design approaches; and perception and management of development project risk (Dang et al. 2019; Kautz et al. 2011; Kautz 2011; Pries-Heje et al. 2008; Bunker et al. 2007).

\section{The Special Issue}

The papers presented in this special issue have been discussed at IFIP 8.6 conference in Portsmouth UK in June 2018, were selected for further rigorous review and where seven papers were finally selected for publications in this special issue. An argument that cuts consistently across these papers is that despite the magic of emerging technology, outcomes are dependent on the formation of sociotechnical systems that could carry technology through successful adoption, efficient and effective use. The papers in this special issue show that 'smartness' is a product of a long journey and not a direct outcome from the adoption of the technology itself.

The first paper is by Peter Bednar and Christine Welch entitled "Sociotechnical Perspectives on Smart Working: Creating Meaningful and Sustainable Systems" (Bednar and Welch 2020). In this paper, authors adopt an individual perspective of smart working reviewing the debate on industry 4.0 and the emerging industry 5.0 and associated technologies. They explore the nature and implications of smart working and sustainability. Bednar and Welch (2020) 
Table 1 Characteristics of smart technology in a neutral context

\begin{tabular}{ll}
\hline Characteristics & Function \\
\hline Real-time information provision. & $\begin{array}{l}\text { Provides real-time analysis and visualisation of data to } \\
\text { users. } \\
\text { Individuality of goods and service provision. }\end{array}$ \\
$\begin{array}{l}\text { Provides profiling of users allowing organisations to } \\
\text { create individualised goods and services. }\end{array}$ \\
$\begin{array}{l}\text { Mobility of data, information and service access. } \\
\text { Follows users anywhere anytime. }\end{array}$ \\
$\begin{array}{l}\text { Locates users and pushes services and goods to them. } \\
\text { Hyper connectivity where devices are continuously } \\
\text { connected to each other and to their users. }\end{array}$ & $\begin{array}{l}\text { Connects users to each other providing seamless data } \\
\text { transfer and processing }\end{array}$ \\
\hline
\end{tabular}

pose and answer important questions regarding from whose point of view smartness is being considered, whether smart system promote sustainable organizations and how design of smart systems should be approached to produce sustainable positive impacts. They adopt a humanistic perspective that is rarely considered in IS research (Sarker et al. 2019). They suggest that we go beyond the fascination of the new and emerging technology and critically argue for the use of contemporary sociotechnical system design where the whole working system is examined and considered rather than only the narrow adoption or use of technology. This includes work design, policies, reward systems and holistic evaluation systems that takes into account individuals, occupational roles, job design, technologies and the organization (Bednar and Welch 2020).

The second paper by Olivia Benfeldt and colleagues is entitled "Data governance as a collective action problem". In this paper, Benfeldt et al. (2020) highlight that the muchcelebrated data analytics systems cannot succeed without good data governance. However, they argue, data governance remains elusive and difficult to achieve in practice. They adopt an engaged scholarship approach to investigate the challenges practitioners face in their adoption of data governance in local government. They discover complex intricate challenges that prevent the adoption and implementation of data governance. These include value, politics and collaboration. They conclude that to be viable in practice, data governance requires a collective action beyond the thinking of a single system or technology (Benfeldt et al. 2020).

The third paper by Prabhsimran Singh and colleagues is entitled "Smart Monitoring and Controlling of Government Policies Using Social Media and Cloud Computing”. Here the authors argue that government can get smarter through improving the ways it engages and responds to the public. They adopt a pragmatic approach to enquiry and combine the capabilities of both cloud computing and social media analytics to develop a low-cost system for the monitoring of public reactions to governmental policies, options for improvements and the developing of future policies. They propose a system and apply it to monitor public reaction in India, to a latest government policy implementation of the Good and Services Tax by Indian government. As described within this paper, the system has achieved encouraging results which could have an impact on efficient policy making (Singh et al. 2020).

The fourth paper by Milad Mirbabaie and colleagues is entitled "Who Sets the Tone? Determining the Impact of Convergence Behaviour Archetypes in Social Media Crisis Communication". In this paper, authors examine the use of Twitter in emergency situations and examine the case study of Manchester Bombing 2017. They adopt both manual content analysis and social network analysis to study convergence behaviour in this incident and develop a number of convergence archetypes for Twitter use in crisis situations. They provide a critical perspective for the use of Twitter in crisis situations highlighting its positive and negative potentials and how both can become amplified when informing the public during a crisis while also causing tensions and threatening social cohesion if not carefully managed (Mirbabaie et al. 2020).

The fifth paper by Bendik Bygstad and colleagues is entitled "Developing and Organizing an Analytics Capability for Patient Flow in a General Hospital". The study examines what it means to develop an analytic capability in healthcare and in particular hospitals. They argue that analytic capability cannot be taken for granted as a result of adopting analytics technology since it includes not only the ability to gather and analyse data but also the extensive use of data with the aim of driving decisions and actions. They adopt an information infrastructure perspective to examine a case study of a new high-tech hospital and show the complexity surrounding the adoption of analytics. They find that analytic processes interact with the hospital logistics processes in a 'sense and respond' way. In addition, the case study reveals that the development of analytics capability goes well beyond the adoption of data analytics technology to the development of analytics teams and the will of administrative and 
clinical decision makers to alter and formulate decisions based on data analytics (Bygstad et al. 2020).

The sixth paper by Khalid Alzadjali and Amany Elbanna is entitled "Smart Institutional Intervention in the Adoption of Digital Infrastructure: The Case of Government Cloud Computing in Oman". The authors adopt an interpretive approach to enquiry to examine the adoption of government cloud computing in Oman and how institutions could possibly intervene to facilitate this adoption. They reveal the institutional forces that influenced this large-scale adoption and their findings surprisingly show that the market rhetoric of efficiency was not as influential in driving the adoption as the mimetic forces (Alzadjali and Elbanna 2020).

The seventh paper by Steven Alter is entitled "Making Sense of Smartness in the Context of Smart Devices and Smart Systems". In this paper, Alter (2020) provides a conceptualization of smartness in relation to purposefully constructed entities including devices and automated systems. The study focuses on the technical capabilities of systems and devices and the principles of smartness in this regard. In this study, Alter (2019) develops a matrix for smart capabilities that allows for rating the level of smart capability in devices and systems. This matrix could inform analysis and design allowing to locate the level of smartness a device and system could technically provide.

\section{Future Research}

This special issue shows the range of research approaches and theoretical underpinnings that could be adopted when examining the impact of technology on working, living and organising. It asserts a constructionist perspective of technology adoption and use that grounds technology determinism claims in the context of adoption and use and shows the influence of the social, organisational and incumbent technology on adoption outcomes.

Future research on new technology could go beyond the rhetoric of technology domination to examine Whose values? Whose ethics? And whose point of view? What functions, features and 'worldview' are embedded in the technology and how these are being adopted -or ignored- in practice (Elbanna 2007). In this regard, future research should go beyond the existence of smart devices and technology to examine how smart users, organisations and policies could come about through the use of these technologies. The trinity of big data, analytics and artificial intelligence (Akter et al. 2019; de Camargo Fiorini et al. 2018; Duan et al. 2019; Dwivedi et al. 2019b; Gupta et al. 2018; Sivarajah et al. 2017) should be put under scrutiny beyond the technology deterministic view of their power to make our world more efficient and effective.

\section{References}

Akter, S., Bandara, R., Hani, U., Wamba, S. F., Foropon, C., \& Papadopoulos, T. (2019). Analytics-based decision-making for service systems: A qualitative study and agenda for future research. International Journal of Information Management, 48, 85-95.

Alter, S. (2020). Making sense of smartness in the context of smart devices and smart systems. Information Systems Frontiers, 22(2). https://doi.org/10.1007/s10796-019-09919-9.

Alzadjali, K., \& Elbanna, A. (2020). Smart institutional intervention in the adoption of digital infrastructure: The case of government cloud computing in Oman. Information Systems Frontiers, 22(2). https:// doi.org/10.1007/s10796-019-09918-w.

Bednar, P. M., \& Welch, C. (2020). Socio-technical perspectives on smart working: Creating meaningful and sustainable systems. Information Systems Frontiers, 22(2). https://doi.org/10.1007/s10796-01909921-1.

Benfeldt, O., Persson, J. S., \& Madsen, S. (2020). Data governance as a collective action problem. Information Systems Frontiers, 22(2). https://doi.org/10.1007/s10796-019-09923-z.

Bunker, D. (2001). A philosophy of information technology and systems (IT \& S) as tools: Tool development context, associated skills and the global technical transfer (GTT) process. Information Systems Frontiers, 3(2), 185-197.

Bunker, D. and Sleigh, A. (2018) 'The future of spatial Systems for Disaster Management' ISCRAM Asia Pacific, Wellington New Zealand November, 2018.

Bunker, D., Kautz, K., \& Nguyen, A. (2007). The role of value compatibility in IT adoption. Journal of Information Technology, 22(1), 6978.

Bunker, D., Kautz, K., \& Anhtuan, A. (2008). An exploration of information systems adoption: Tools and skills as cultural artefacts - the case of a management information system. Journal of Information Technology, 23(2), 71-78.

Bunker, D., Levine, L., \& Woody, C. (2015). Repertoires of collaboration for common operating pictures of disasters and extreme events. Information Systems Frontiers, 17(1), 51-65.

Bunker, D., Ehnis, C. and Shahbazi, M. (2019a) Managing influenza outbreaks through social interaction on social media: Research transformation through an engaged scholarship approach. Healthcare of the Future, 5 April 2019, Biel/Bienne, Switzerland.

Bunker, D., Stieglitz, S., Ehnis, C. and Sleigh, A. (2019b) 'Bright ICT: Social Media Analytics for Society and Crisis Management' In: Dwivedi Y., Ayaburi E., Boateng R., Effah J. (eds) ICT Unbounded, Social Impact of Bright ICT Adoption. TDIT 2019. IFIP advances in information and communication technology, vol 558. Springer, Cham. /10.1007/978-3-030-20671-0_37.

Bygstad, B., Øvrelid, E., Lie, T., \& Bergquist, M. (2020). Developing and organizing an analytics capability for patient flow in a general hospital. Information Systems Frontiers, 22(2). https://doi.org/10.1007/ s10796-019-09920-2.

Dang, D., Pittayachawan, S., Bruno, V., \& Kautz, K. (2019). Investigating the diffusion of IT consumerization in the workplace: A case study using social network analysis. Information Systems Frontiers, 21(4), 941-955.

Davis, F. D. (1989). Perceived usefulness, perceived ease of use and user acceptance of information technology. MIS Quarterly, 13(3), 319339.

de Camargo Fiorini, P., Seles, B. M. R. P., Jabbour, C. J. C., Mariano, E. B., \& de Sousa Jabbour, A. B. L. (2018). Management theory and big data literature: From a review to a research agenda. International Journal of Information Management, 43, 112-129.

Duan, Y., Edwards, J. S., \& Dwivedi, Y. K. (2019). Artificial intelligence for decision making in the era of big data-evolution, challenges and 
research agenda. International Journal of Information Management, 48, 63-71.

Dwivedi, Y. K., Wastell, D., Laumer, S., Henriksen, H. Z., Myers, M. D., Bunker, D., \& Srivastava, S. C. (2015). Research on information systems failures and successes: Status update and future directions. Information Systems Frontiers, 17(1), 143-157.

Dwivedi, Y. K., Rana, N. P., Jeyaraj, A., Clement, M., \& Williams, M. D. (2019a). Re-examining the unified theory of acceptance and use of technology (UTAUT): Towards a revised theoretical model. Information Systems Frontiers, 21(3), 719-734.

Dwivedi, Y. K., Hughes, L., Ismagilova, E., Aarts, G., Coombs, C., Crick, T. \& Galanos, V. (2019b). Artificial Intelligence (AI): Multidisciplinary perspectives on emerging challenges, opportunities, and agenda for research, practice and policy. International Journal of Information Management. https://doi.org/10.1016/j. ijinfomgt.2019.08.002, Artificial Intelligence (AI): Multidisciplinary perspectives on emerging challenges, opportunities, and agenda for research, practice and policy.

Ehnis, C., Bunker, D. (2019). Repertoires of collaboration: Incorporation of social media help requests into the common operating picture. Behaviour and Information Technology, published online: 29 may 2019.

Elbanna, A. R. (2007). Implementing an integrated system in a socially dis-integrated enterprise: A critical view of ERP enabled integration. Information Technology and People, 20(2), 121-139.

Elbanna, A. R. (2008). Strategic systems implementation: Diffusion through drift. Journal of Information Technology, 23, 89-96.

Elbanna, A., \& Linderoth, H. C. J. (2015). The formation of technology mental models: The case of voluntary use of technology in organizational setting. Information Systems Frontier, 17, 95-108.

Elbanna, A., Bunker, D., Levine, L., \& Sleigh, A. (2019). Emergency management in the changing world of social media: Framing the research agenda with the stakeholders through engaged scholarship. International Journal of Information Management, 47, 112-120.

Gupta, S., Kar, A. K., Baabdullah, A., \& Al-Khowaiter, W. A. (2018). Big data with cognitive computing: A review for the future. International Journal of Information Management, 42, 78-89.

Hughes, L., Dwivedi, Y. K., Misra, S. K., Rana, N. P., Raghavan, V., \& Akella, V. (2019). Blockchain research, practice and policy: Applications, benefits, limitations, emerging research themes and research agenda. International Journal of Information Management, 49, 114-129.

Ismagilova, E., Hughes, L., Dwivedi, Y. K., \& Raman, K. R. (2019a). Smart cities: Advances in research-An information systems perspective. International Journal of Information Management, 47, $88-100$.

Ismagilova, E., Hughes, L., Rana, N., \& Dwivedi, Y. (2019b). Role of smart cities in creating sustainable cities and communities: A systematic review. In ICT unbounded, social impact of bright ICT adoption: IFIP WG 8.6 International Conference on Transfer and Diffusion of IT, TDIT 2019, Accra, Ghana, June 21-22, 2019, proceedings (p. 311). Springer.

Kaniadakis, A., and Elbanna, A. 2019. Thinking transparency in European securitization: Repurposing the Market's information infrastructures, in Thinking Infrastructures, M. Kornberger, G. C. Bowker, J. Elyachar, A. Mennicken, P. miller, J. R. Nucho and N. Pollock (eds.), emerald Publishng limited, pp. 183-205.

Kautz, K. (2011). Investigating the design process: Participatory design in agile software development. Information Technology and People, 24(3), 217-235.

Kautz, K., Bunker, D., Rab, S., Sinnet, M. (2011). Investigating open innovation and Interorganizational networks in the IT industry: The case of standard software customization. In Mike Chiasson, Ola Henfridsson, Helena Karsten and Janice I. DeGross (Eds.), Researching the future in information systems - IFIP WG 8.2 working conference, Turku, Finland, June 6-8, 2011 - proceedings, (pp. 231-246). London, United Kingdom: Springer.

Kim, J. Y., Hlee, S., \& Joun, Y. (2016). Green practices of the hotel industry: Analysis through the windows of smart tourism system. International Journal of Information Management, 36(6), 1340 1349.

McMaster, T., \& Wastell, D. (2005). Diffusion-or delusion? Challenging an IS research tradition. Information Technology \& People, 18(4), 383-404.

Mirbabaie, M., Bunker, D., Stieglitz, S., \& Deubel, A. (2020). Who sets the tone? Determining the impact of convergence behaviour archetypes in social media crisis communication. Information Systems Frontiers, 22(2). https://doi.org/10.1007/s10796-019-09917-x.

Papagiannidis, S., \& Marikyan, D. (2019). Smart offices: A productivity and well-being perspective. International Journal of Information Management., 51, 102027. https://doi.org/10.1016/j.ijinfomgt. 2019.10.012.

Pries-Heje, J., Levine, L., Baskerville, R., \& Ramesh, B. (2008). Advances in information systems development: From discipline and predictability to agility and improvisation. In D. Avison, G.M. Kasper, B. Pernici, I. Ramos \& D. Roode (Eds.), advances in information systems research, education and practice (pp. 53-75). New York: Springer. [IFIP advances in information and communication technology, 274, 53-75.

Rana, N. P., Luthra, S., Mangla, S. K., Islam, R., Roderick, S., \& Dwivedi, Y. K. (2019). Barriers to the development of smart cities in Indian context. Information Systems Frontiers, 21(3), 503-525.

Rogers, E. M. (2003). Diffusion of innovations (5th ed.). New York: Free Press.

Sarker, S., Chatterjee, S., Xiao, X., \& Elbanna, A. (2019). The sociotechnical axis of cohesion for the is discipline: Its historical legacy and its continued relevance. MIS Quarterly, 43(3), 695-719.

Singh, P., Dwivedi, Y. K., Kahlon, K. S., Sawhney, R. S., Alalwan, A. A \& Rana, N. P. (2020). Smart monitoring and controlling of government policies using social media and cloud computing. Information Systems Frontiers, 22(2). https://doi.org/10.1007/s10796-01909916-y.

Sivarajah, U., Kamal, M. M., Irani, Z., \& Weerakkody, V. (2017). Critical analysis of big data challenges and analytical methods. Journal of Business Research, 70, 263-286.

Stieglitz, S., Bunker, D., Mirbabaie, M., \& Ehnis, C. (2018). Sensemaking in social media during extreme events. Journal of Contingencies and Crisis Management, 26(1), 4-15.

Venkatesh, V., Morris, M. G., Davis, G. B., \& Davis, F. D. (2003). User acceptance of information technology: Toward a unified view. MIS Quarterly, 27(3), 425-478.

Wastell, D. 1999. The human dimension of the software process, in Software Process: Principles, Methodology, and Technology, Springer, pp. 165-199.

Wastell, D. G. (2003). Organizational discourse as a social defense: Taming the tiger of electronic government, in Global and organizational discourse about information technology, Springer, pp. 179195.

Wastell. (2011). Managers as designers in the public services: Beyond Technomagic. Axminster: Triarchy Press.

Wastell, D. G., \& Cooper, C. L. (1996). Stress and technological innovation: A comparative study of design practices and implementation strategies. European Journal of Work and Organizational Psychology, 5(3), 377-397.

Wastell, D., Kawalek, P., Langmead-Jones, P., \& Ormerod, R. (2004). Information systems and partnership in multi-agency networks: An action research project in crime reduction. Information and Organization, 14(3), 189-210. 
Publisher's Note Springer Nature remains neutral with regard to jurisdictional claims in published maps and institutional affiliations.

Amany Elbanna is a Reader (Associate Professor) at Royal Holloway University of London. Her current research examines digital platforms, digital entrepreneurship and crowdsourcing. Amany is an Associate Editor of Information Systems Journal and a member of the Editorial Board of Information \& Management, Journal of the Association of Information Systems (JAIS), Information Technology \& People, Scandinavian Journal of Information Systems and Journal of Enterprise Information Management. Her work is published in leading academic journals including the MIS Quarterly, European Journal of Information Systems, the Journal of Strategic Information Systems, Journal of Information Technology, IEEE Software, The Data Base, Information Technology and People among others. Amany is a regular speaker in industry and her research is featured in The Financial Times, Computer Weekly and The Manufacturing Magazine. She is the current Directorelect of Professional Development for the UK Chapter of the Association of Change Management. Professionals and the Vice Chair of IFIP WG8.6 on Diffusion and Adoption of Technology.

Yogesh Dwivedi is a Professor of Digital Marketing and Innovation, Founding Director of the Emerging Markets Research Centre (EMaRC) and Co-Director of Research at the School of Management, Swansea University, Wales, UK. Professor Dwivedi is also currently leading the International Journal of Information Management as its Editor-in-Chief. His research interests are at the interface of Information Systems (IS) and Marketing, focusing on issues related to consumer adoption and diffusion of emerging digital innovations, digital government, and digital marketing particularly in the context of emerging markets. Professor Dwivedi has published more than 300 articles in a range of leading academic journals and conferences that are widely cited (more than 15 thousand times as per Google Scholar). Professor Dwivedi is an Associate Editor of the European Journal of Marketing, Government Information Quarterly and International Journal of Electronic Government Research, and Senior Editor of the Journal of Electronic Commerce Research. More information about Professor Dwivedi can be found at: http://www. swansea.ac.uk/staff/som/academic-staff/y.k.dwivedi/.

Deborah Bunker is a leading international scholar in organizational collaboration and change management in complex organizational and environmental settings. She is a Chief Investigator on an EU Horizon 2020 project RISE_SMA Social Media Analytics for Society and Crisis Communication and a Norwegian Research Council SAMRISK Work Program project INSITU Sharing Incident and Threat Information During Crises. Deborah is Chair and Convener of the Communications and Technology for Society Research Group and immediate past Chair of the International Federation of Information Processing (IFIP) Working Group 8.6 (Transfer and Diffusion of IT). She is also a MultiDisciplinary Advisory Board Member of the Marie Bashir Institute (MBI) at the University of Sydney, Member of the Research Evaluation Committee (Mathematics, Information and Computing Sciences Panel) for the Excellence in Research for Australia evaluation process (ERA 2018, 2015), Past President (2012-2014) of the Australian Council of Professors and Heads of IS (ACPHIS) and General (2011, 2014), Program $(2005,2011,2019)$ and Doctoral Consortium (2017) Chair of the Australasian Conference in Information Systems. She has been a Track Co-Chair for the International Conference on IS (ICIS 2015, 2018) and was also a Program Co-Chair for the inaugural ICSRAM Asia Pacific Conference in Wellington, in November 2018. Professor Bunker is Senior Editor for Information Technology and People and is also a Section Editor for the Australasian Journal of Information Systems.

David Wastell is Emeritus Professor of Information Systems at Nottingham University Business School. His previous career involved positions at the universities of Manchester and Salford, and UMIST. He was President of the UK Academy of Information Systems, 2014-2016, and is a former vice-president of IFIP WG8.6, an international research group concerned with technology adoption and transfer. David has organized numerous international conferences and other colloquia, publishing widely in a spectrum of research journals. His current research interests include 1) service design and innovation in the public sector, 2) the cognitive engineering of complex human-machine systems, and 3) critical commentary on the impact of the new biotechnologies on UK social policy. Recent co-authored books include "Blinded by Science: the social implications of epigenetics and neuroscience" (2017, with Sue White) and "Reassessing attachment theory in child welfare" (2020, with White, Gibson and Walsh), both published by Policy Press. He is currently working on a revision of his 2011 book ("Managers as designers in the public services: beyond technomagic") which expounds a sociotechnical approach to systems design and is aimed at managers and policy-makers (also to be published by Policy Press). 